\title{
Steric and Electronic Effects of Electrochemically Generated Aryl Radicals on Grafting of Graphite Surface
}

Kazukuni Tahara, ${ }^{* 1,2,3}$ Yuki Kubo, ${ }^{1}$ Benjamin Lindner, ${ }^{1}$ Shingo Hashimoto, ${ }^{2}$ Shingo Hirose, ${ }^{2}$ Anton Brown, ${ }^{4}$ Brandon Hirsch, ${ }^{4}$ Lakshya Daukiya, ${ }^{4}$ Steven De Feyter*,4 and Yoshito Tobe, ${ }^{*, 1,5}$

1. Division of Frontier Materials Science, Graduate School of Engineering Science, Osaka University, Toyonaka, Osaka 560-8531, Japan.

2. Department of Applied Chemistry, School of Science and Technology, Meiji University, 1-1-1 Higashimita, Tama-ku, Kawasaki, Kanagawa 214-8571, Japan.

3. PRESTO, Japan Science and Technology Agency, 4-1-8, Honcho, Kawaguchi, Saitama 332-0012, Japan.

4. Division of Molecular Imaging and Photonics, Department of Chemistry, KU Leuven, Celestijnenlaan 200F, 3001 Leuven, Belgium.

5. The institute of Scientific and Industrial Research, Osaka University, Ibaraki, 567-0047, Osaka, Japan.

\begin{abstract}
Surface grafting of aryl radicals generated by electrochemical reduction of aryldiazonium salts has been extensively studied on various surfaces. However, there exits two unclear aspects; the first one is the generality of the blocking ability of simple functional groups towards multi-layer growth, and the second one is the electronic impact of substituent groups of aryl radicals on grafting efficiency. To address these aspects, we have studied the electrochemical functionalization of graphite using aryldiazonium salts having electron-donating or -withdrawing groups at the 3,4,5-positions. AFM investigation of the functionalized surfaces revealed the formation of monolayers for all aryldiazonium salts, and thus nitro, carboxy, ester, methyl and methoxy groups at the 3,4,5-positions of the benzene ring suppress polyaryl growth. The degree of grafting estimated by STM imaging and Raman spectroscopy of the functionalized surfaces depends on the electronic state of the aryl radicals, in which the radicals with electron-donating groups show a high degree of functionalization, while those with electron-withdrawing groups exhibit a low degree of functionalization. We discuss several possibilities that affect grafting density. Though there are several factors, we hypothesize that one factor to explain the observed reactivity trend is the electronic property of the aryl radicals, namely the relative position of the singly-occupied molecular orbital (SOMO) energy levels of the aryl radicals with respect to the graphite Fermi energy level.
\end{abstract}




\section{INTRODUCTION}

Covalent functionalization of surfaces using aryldiazonium salts has attracted great interest because this allows modifying the properties of these surfaces towards applications in molecular electronics, ${ }^{1}$ supercapacitors and batteries, ${ }^{2,3}$ sensors ${ }^{4}$ surface patterning ${ }^{5}$ and inks. ${ }^{6}$ One of the advantages is the broad range of substituents the covalent functionalization protocol is compatible with, so that the physical and chemical properties can be tailored based on the selection of these substituents. Moreover, various surfaces including metals, carbon, and semiconductor surfaces can be covalently functionalized. ${ }^{7,8}$

Surface covalent functionalization or grafting occurs through generation of aryl radicals by a one-electron reduction of aryldiazonium salts. Spontaneous grafting of aryl radicals by substrate mediated reduction of aryldiazonium salts is simple and easy, however, its reaction efficiency remains low and depends on the reducing ability of the substrate with respect to the aryldiazonium salts. ${ }^{9-11}$ Compared to spontaneous grafting, surface grafting of aryl radicals generated by electrochemical (EC) reduction of aryldiazonium salts has been extensively studied. ${ }^{9,12,13}$ This reaction is typically conducted in an EC cell, in which an aryldiazonium salt is dissolved in an electrolyte solution and a (semi)conductive surface is used as a working electrode. Reduction occurs at the vicinity of the working electrode leading to high grafting density. Various macroscopic and microscopic characterization methods are applicable to analyze these functionalized surfaces. ${ }^{14}$ Macroscopic methods such as EC measurements, X-ray photoelectron spectroscopy, infrared and Raman spectroscopy, quartz crystal microbalance measurement and ellipsometry, and microscopy methods such as atomic force microscopy (AFM) revealed that the thickness of the grafted layers depends on the substituents on the aryl groups. ${ }^{15-21}$ Another microscopy technique, scanning tunneling microscopy (STM), allows to precisely locate the grafting sites. ${ }^{22,23}$

We recently engaged in the investigation of grafted graphite and graphene surfaces by means of direct observations with STM and AFM. ${ }^{23}$ These observations confirmed that electrochemically generated aryl radicals from 4-nitrobenzene-1-diazonium tetrafluoroborate $\mathbf{1 b} \cdot \mathbf{B F} 4$ form a multi-layered film with low grafting density, while 3,5-di-tert-butylbenzene-1-diazonium chloride $\mathbf{2 b} \cdot \mathbf{C l}$ afford a monolayer with very high grafting density (Figure 1). These previous works by us and other groups suggest that hydrogen atom(s) at the 3,4,5-position(s) of the grafted benzene ring are subject to substitution reactions with the aryl radicals to form a dendritic structure. This multi-layer growth and surface grafting occur in a competitive manner, resulting in a low grafting density. On the other hand, bulky tert-butyl groups at the 3,5-positions of $\mathbf{2} \mathbf{b} \cdot \mathbf{C l}$ block this dendritic growth, leading to monolayer formation with remarkably high grafting density. ${ }^{18,19}$ Similarly, other bulky groups, such as (trialkylsilyl)ethynyl groups and an alkoxylated calixarene scaffold, are also known to block 
multilayer growth. ${ }^{24-28}$ Another approach to suppress multi-layer formation is addition of a radical scavenger during EC reduction of aryldiazonium salts. ${ }^{29-31}$

Despite these studies, two aspects remain unclear. The first one is the generality of the blocking ability of simple functional groups towards multi-layer growth if they are located at the positions which are otherwise subjected to further attack by aryl radicals. The second one is the electronic impact of substituent groups of aryl radicals on grafting efficiency. ${ }^{10,32-34}$ The relative reactivities of grafting on gold electrodes by aryl radicals bearing a substituent of different electronic properties at the 4-position has been evaluated recently by measuring initial rates. ${ }^{35}$ Plotting initial reaction rates with respect to the Hammett substituent $\sigma$ constants showed a reasonable linear trend, though it turned out difficult to compare grafting densities owing to the competitive multi-layer growth. Such reactivity comparison of aryl radicals having different electronic character has yet to be reported for graphitic surfaces. The substituent effect of aryldiazonium salts on the thickness of produced films on graphitic surfaces after EC reduction was reported in the absence and presence of the radical scavenger, ${ }^{36}$ yet the surface grafting densities were not evaluated. It is therefore of interest to address these issues for the precise property tuning of various substances.

In this respect, we became interested in the nanoscale characterization of grafted layers formed by EC reduction of aryldiazonium salts $\mathbf{3 b} \cdot \mathbf{C l}-\mathbf{7 b} \cdot \mathbf{C l}$ (Figure 2). These aryldiazonium salts prepared from aniline derivatives 3a-7a bear functional groups at the 3,4,5-positions of the benzene ring and will shed light on the blocking ability of these functional groups and EC grafting efficiency of the corresponding aryl radicals. We employed graphite as a representative surface, since covalent functionalization of graphitic substances including graphene has attracted great interest. ${ }^{37-39}$ Moreover, graphite is the most accessible and least reactive flat carbon substrate.

In this study, AFM observation of all grafted layers revealed exclusive formation of monolayers. This confirms that the nitro, carboxy, ester, methyl and methoxy substituent groups suppress multilayer growth irrespective of their electronic properties when they are located at the 3,4,5-positions. Moreover, the grafting densities determined by STM observations and Raman spectroscopy analyses of the grafted surfaces indicate the following reactivity trend of the aryl radicals; radicals with electron-donating groups graft the surface with higher efficiency compared to those with electron-withdrawing groups. We discuss several possibilities that affect grafting density. Though there are several factors, we suggest that one factor to explain the observed reactivity trend is the electronic property of the aryl radicals, namely the relative position of the singly-occupied molecular orbital (SOMO) energy levels of the aryl radicals with respect to the graphite Fermi energy level. Present study provides useful information for chemical functionalization of various surfaces to tailor their properties. 


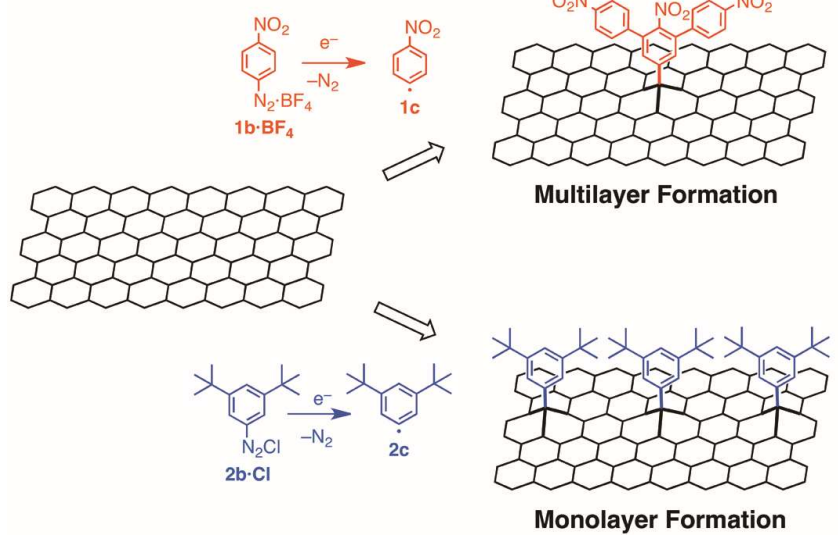

Figure 1. Schematic representation for chemical functionalization of graphitic surfaces through aryl radical addition reactions. 4-Nitrophenyl radical 1c results in multi-layer growth with a low grafting density, while 3,5-di-tert-butylphenyl radical 2c shows monolayer formation with a high grafting density.<smiles>[X]c1cc(OC)c(OC)c(OC)c1</smiles><smiles>[X]c1cc(C)c(C)c(C)c1</smiles><smiles>[X]c1cc(C(=O)OC)c(C(=O)OC)c(C(=O)OC)c1</smiles><smiles>[X]c1cc(C(=O)O)c(C(=O)O)c(C(=O)O)c1</smiles><smiles>[X]c1cc([N+](=O)[O-])c(C)c([N+](=O)[O-])c1</smiles>

3a, $\mathrm{X}=\mathrm{NH}_{2}$

4a, $\mathrm{X}=\mathrm{NH}_{2}$

5a, $X=\mathrm{NH}_{2}$

6a, $Y=\mathrm{NH}_{2}$

$5 \mathbf{b}, \mathrm{X}=\mathrm{N}_{2}^{+}$

$6 \mathbf{b}, \mathrm{Y}=\mathrm{N}_{2}^{+}$

$7 a, X=\mathrm{NH}_{2}$
$7 b, X=\mathrm{N}_{2}{ }^{+}$<smiles>COc1cc(C)cc(OC)c1OC</smiles><smiles>Cc1cc(C)c(C)c(C)c1</smiles><smiles>COC(=O)c1cc([18O])cc(C(=O)OC)c1C(=O)OC</smiles><smiles>O=C(O)c1c[14c]([18O])[14cH][14c](C(=O)O)c1C(=O)O</smiles><smiles>Cc1c([N+](=O)[O-])cc([13CH3])cc1[N+](=O)[O-]</smiles>

Figure 2. Chemical structures of aniline derivatives $\mathbf{3 a}-\mathbf{7 a}$, aryldiazonium ions $\mathbf{3 b}-\mathbf{7 b}$, and aryl radicals $\mathbf{3 c}-\mathbf{7 c}$.

\section{RESULTS}

\section{Selection of Aryldiazonium Salts}

Because either of the 3,4,5-positions of the grafted aryl groups can be subject to further attack of aryl radicals, hydrogen atoms at these positions are substituted by functional groups. We chose common functional groups having an electron-donating or -withdrawing character. Electronic effects of functional groups in benzene derivatives are often referred to the Hammett $\sigma$ substituent 
constants in the Hammett equation and its extended forms, ${ }^{40}$ showing a clear trend and a quantitative estimate of the electron-donating or electron-withdrawing properties of these substituents. ${ }^{40} \mathrm{On}$ the basis of such trend, following aniline derivatives were employed as the precursors of aryldiazonium salts: 3,4,5-trimethoxyaniline (3a) and 3,4,5-trimethylaniline (4a) as electron-rich precursors and trimethyl 5-amino-1,2,3-benzenetricarboxylate (5a), 5-amino-1,2,3-benzenetricarboxlic acid (6a) and 3,5-dinitro-4-methylaniline (7a) as electron-deficient substrates, taking compound availability into account (Figure 2). Though surface grafting with $\mathbf{3 c}$ was reported before, ${ }^{41,42}$ yet these studies did not characterize the grafted layers at the nanometer scale. Commercially available anilines 3a, 4a, 6a, and 7a were used as received. Aniline 5a was synthesized from 6a by esterification (see Supporting Information). In addition, 3,5-di-tert-butylaniline (2a) was used as a reference compound. ${ }^{18,19,23}$

To predict the electronic effect of the functional groups on the frontier orbitals of the aryldiazonium ions and aryl radicals, we performed density functional theory (DFT) calculations of aryldiazonium ions $\mathbf{2 b}-\mathbf{7 b}$ and aryl radicals $\mathbf{2 c - 7 c}$ using the M06-2X/6-311+G(3df, 2p) level of theory. Table 1 summarizes the highest occupied molecular orbital (HOMO) and the lowest unoccupied molecular orbital (LUMO) energy levels of $\mathbf{2 b}-\mathbf{7 b}$ and SOMO and LUMO energy levels of $\mathbf{2 c - 7 c}$. The functional groups effectively modulate the energy levels of these orbitals of both species. The energy level orders are as follows: $\mathbf{7 b}<\mathbf{6 b}<\mathbf{5 b}<\mathbf{4 b}<\mathbf{2 b}<\mathbf{3 b}$ for the LUMO energy levels and 7c $<\mathbf{6 c}<\mathbf{5 c}<\mathbf{4 c}<\mathbf{2 c}<\mathbf{3 c}$ for the SOMO energy levels in accordance with the known electronic properties of the substituents as stated above. ${ }^{35}$ HOMO and LUMO distributions of aryldiazonium ions are shown in Figure S1. SOMO distributions and spin densities shown in Figure S2 confirm that for all aryl radicals an unpaired electron is accommodated in one of the $s p^{2}$-hybridized orbitals of carbon rather than in the $p$-orbitals ( $\sigma$-radical). ${ }^{43}$ 
Table 1. Estimated HOMO and LUMO Energy Levels of Aryldiazonium Ions $\mathbf{2 b}-\mathbf{7 b}$ and SOMO and LUMO Energy Levels of Aryl Radicals 2c-7c by DFT Calculations.

\begin{tabular}{|c|c|c|c|c|c|}
\hline & & \multicolumn{2}{|c|}{ aryldiazonium ion } & \multicolumn{2}{c|}{ aryl radical } \\
\hline \multirow{2}{*}{ compound } & substituents & $\begin{array}{c}\text { HOMO level } \\
(\mathrm{eV})\end{array}$ & $\begin{array}{c}\text { LUMO level } \\
(\mathrm{eV})\end{array}$ & $\begin{array}{c}\text { SOMO level } \\
(\mathrm{eV})\end{array}$ & $\begin{array}{c}\text { LUMO level } \\
(\mathrm{eV})\end{array}$ \\
\hline $\mathbf{2}$ & $\mathrm{C}\left(\mathrm{CH}_{3}\right)_{3}{ }^{a}$ & -12.7 & -6.30 & -7.89 & 0.18 \\
\hline $\mathbf{3}$ & $\mathrm{OCH}_{3}$ & -11.4 & -6.00 & -7.58 & 0.29 \\
\hline $\mathbf{4}$ & $\mathrm{CH}_{3}$ & -12.9 & -6.38 & -7.99 & 0.28 \\
\hline $\mathbf{5}$ & $\mathrm{COOCH}_{3}{ }^{a}$ & -13.0 & -6.82 & -8.77 & -1.23 \\
\hline $\mathbf{6}$ & $\mathrm{COOH}^{a}$ & -13.4 & -7.11 & -9.02 & -1.52 \\
\hline $\mathbf{7}$ & $\mathrm{NO}_{2}, \mathrm{CH}_{3}$ & -14.4 & -7.62 & -9.69 & -2.15 \\
\hline
\end{tabular}

${ }^{a}$ Energy levels of the lowest energy isomers among three conformers. Energy levels of other isomers are shown in Figures S1 and S2 and Tables S1 and S2 in Supporting Information.

Table 2. Half-Life Time $\left(t_{1 / 2}\right)$ of In-Situ Prepared Aryldiazonium Salts $\mathbf{2 b} \cdot \mathbf{C l}-\mathbf{7 b} \cdot \mathbf{C l}$.

\begin{tabular}{|c|c|c|c|}
\hline \multirow[b]{2}{*}{$\begin{array}{l}\text { aniline } \\
(0.1 \mathrm{mM})\end{array}$} & \multirow[b]{2}{*}{ substituents } & \multicolumn{2}{|c|}{$\mathrm{NaNO}_{2}$} \\
\hline & & $\begin{array}{c}\text { high } \\
\text { concentration } \\
(2 \mathrm{mM})\end{array}$ & $\begin{array}{c}\text { low } \\
\text { concentration } \\
(0.2 \mathrm{mM})\end{array}$ \\
\hline $2 a$ & $\mathrm{C}\left(\mathrm{CH}_{3}\right)_{3}$ & $\begin{array}{c}\text { very slow } \\
\text { degradation }\end{array}$ & $\begin{array}{c}\text { very slow } \\
\text { degradation }\end{array}$ \\
\hline $3 a$ & $\mathrm{OCH}_{3}$ & $898 \mathrm{~min}$ & $1306 \mathrm{~min}$ \\
\hline $4 a$ & $\mathrm{CH}_{3}$ & $\begin{array}{c}\text { slow } \\
\text { degradation }\end{array}$ & $116 \mathrm{~min}$ \\
\hline $5 a$ & $\mathrm{COOCH}_{3}$ & $125 \mathrm{~min}$ & $116 \mathrm{~min}$ \\
\hline $6 a$ & $\mathrm{COOH}$ & $669 \mathrm{~min}$ & $465 \mathrm{~min}$ \\
\hline $7 a$ & $\mathrm{NO}_{2}, \mathrm{CH}_{3}$ & ca. $10 \mathrm{~min}$ & $5-10 \min$ \\
\hline
\end{tabular}




\section{Preparation of Aryldiazonium Salts}

First, we investigated the formation and stability of the aryldiazonium salts in aqueous solution. UV-Vis absorption spectra of the aqueous solutions of the substituted aniline hydrochlorides $(0.10 \mathrm{mM})$ and $\mathrm{NaNO}_{2}(0.20 \mathrm{mM}$ or $2.0 \mathrm{mM})$ were monitored at ambient temperature. The formation of all aryldiazonium salts is fast, within $5 \mathrm{~min}$ for compounds $\mathbf{2 b} \cdot \mathbf{C l}, \mathbf{3 b} \cdot \mathbf{C l}, \mathbf{5 b} \cdot \mathbf{C l}$, and $\mathbf{6 b} \cdot \mathbf{C l}$, and 20 min for compounds $\mathbf{4 b}$ and $\mathbf{7 b}$. Except for compound $\mathbf{7 b} \cdot \mathbf{C l}$, the half-life time of the aryldiazonium salts is longer than $100 \mathrm{~min}$, which is long enough to perform subsequent EC treatments (see Figures S4-S8). In the case of $\mathbf{7 b} \cdot \mathbf{C l}$, the immediate formation of a byproduct, probably an azobenzene derivative or charge transfer complex ${ }^{44}$ was observed just after mixing, and therefore the half-life time of $\mathbf{7 b} \cdot \mathbf{C l}$ is very short (ca. $10 \mathrm{~min}$, Figure S9). This inferior stability is attributed to the high electrophilicity of this aryldiazonium salt (Table 1$).{ }^{45}$

Just before EC treatment, aryldiazonium salts were prepared by the addition of an aqueous solution of $\mathrm{NaNO}_{2}(0.1 \mathrm{M}, 0.1 \mathrm{~mL})$ to a mixture of an aniline derivative $(1.0 \mathrm{mM})$ and $\mathrm{HCl}(50 \mathrm{mM})$ in water $(5.0 \mathrm{~mL})$. The concentrations of the aniline derivatives and $\mathrm{NaNO}_{2}$ are ten times larger than those used for the UV studies, in which the formation of the most of aryldiazonium salts is completed within $5 \mathrm{~min}$. At the higher concentrations used for the electrochemical reactions, we assume that the aryldiazonium salts formation already completed within $5 \mathrm{~min}$. At the higher concentrations used for the electrochemical reactions, we assume that aryldiazonium salts formation in already completed after a few minutes. The mixture was shaken by hand for $30 \mathrm{sec}$. for the preparation of aryldiazonium salts $\mathbf{2 b} \cdot \mathbf{C l}-\mathbf{6 b} \cdot \mathbf{C l}$. Then the mixture was added to a home-built EC cell in which a $\mathrm{Ag} / \mathrm{AgCl}$ reference electrode, a Pt counter electrode and a highly oriented pyrolytic graphite (HOPG) working electrode were integrated. ${ }^{23}$ After 3 min from mixing (for $\mathbf{2 b} \cdot \mathbf{C l}-\mathbf{6} \mathbf{b} \cdot \mathbf{C l}$ ), EC reduction was carried out in the cyclic voltammetry $(\mathrm{CV})$ mode. In the case of 7a, EC treatment was performed just after mixing in order to minimize the decomposition. In $\mathrm{CV}$, the sweep potential ranges were adjusted to cover the reduction potentials of the aryldiazonium salts. Typically, negative overpotentials of $-0.3 \mathrm{~V}$ - $-0.5 \mathrm{~V}$ from current peak maximums $\left(E_{\mathrm{pc}}\right)$ of the reduction waves of the aryldiazonium salts were applied to maximize the reduction of the aryldiazonium salts and avoid the reduction of the aryl radicals. $^{46}$

\section{Electrochemical Reduction of Aryldiazonium Salts}

All aryldiazonium salts showed irreversible single one-electron reduction waves (Figure 3). Table 3 summarizes the reduction potentials of the aryldiazonium salts against a $\mathrm{Ag} / \mathrm{AgCl}$ reference electrode. Compound $\mathbf{3 a} \cdot \mathbf{C l}$ with electron-donating methoxy groups showed a reduction wave at $E_{\mathrm{pc}}$ $=-0.16 \mathrm{~V}$ (Figure $3 \mathrm{a}$ ). This potential is comparable to that of compound $\mathbf{2 a} \cdot \mathbf{C l}\left(E_{\mathrm{pc}}=-0.17 \mathrm{~V}\right)$. 
Compound $\mathbf{4 b} \cdot \mathbf{C l}$ having methyl groups was reduced at a slightly more positive potential $\left(E_{\mathrm{pc}}=-0.12\right.$ $\mathrm{V}$, Figure $3 \mathrm{~b}$ ) reflecting the weaker electron-donating ability of the methyl groups. In contrast, the compounds having electron-withdrawing groups showed reduction waves at positive potentials. Compound $\mathbf{6 b} \cdot \mathbf{C l}$ with carboxy groups was reduced at $E_{\mathrm{pc}}=0.24 \mathrm{~V}$ (Figure $3 \mathrm{~d}$ ). The ester groups of compound $\mathbf{5 b} \cdot \mathbf{C l}$ led to a further positive shift of the reduction potential to $E_{\mathrm{pc}}=0.34 \mathrm{~V}$ (Figure $3 \mathrm{c}$ ). In this series of compounds, compound $\mathbf{7 b} \cdot \mathbf{C l}$ was reduced at the most positive potential $\left(E_{\mathrm{pc}}=0.42\right.$ V) owing to the strong electron-withdrawing nature of the nitro groups (Figure 3e). This confirms that the substituent groups significantly influence the reduction potentials, in agreement with the previous studies in which the reduction potentials of the aryldiazonium salts correlate with the $\sigma$ substituent constants in the Hammett equation. ${ }^{47,48}$ Further second reduction peaks with aryl radicals were not observed for selected potential ranges. ${ }^{46,48}$ The amount of the current flow is reduced significantly in consecutive cycles for all compounds, indicating that grafted layers act as potential barriers for further reduction. ${ }^{16,17,19,20,23}$

Previously, two reduction mechanisms of aryldiazonium salts to aryl radicals were proposed, a stepwise mechanism where an aryldiazenyl radical is formed as an intermediate and a concerted mechanism where aryl radicals are directly produced. ${ }^{46,48}$ The stepwise mechanism was based on the observation of the aryldiazenyl radicals in the reduction of aryldiazonium salts by strong reducing species, solvated electrons, generated by pulse radiolysis in water. ${ }^{49}$ However, for electrochemical reduction of benzenediazonium salt and mono-substituted aryldiazonium salts at para-position (nitro and methyl groups), it was concluded that the reduction of these compounds occurred through the concerted mechanism. ${ }^{48}$ In our case, therefore, we consider that all aryl radicals are formed directly upon reduction through the concerted mechanism, though further detailed electrochemical study is necessary to clarify the reduction mechanism. 

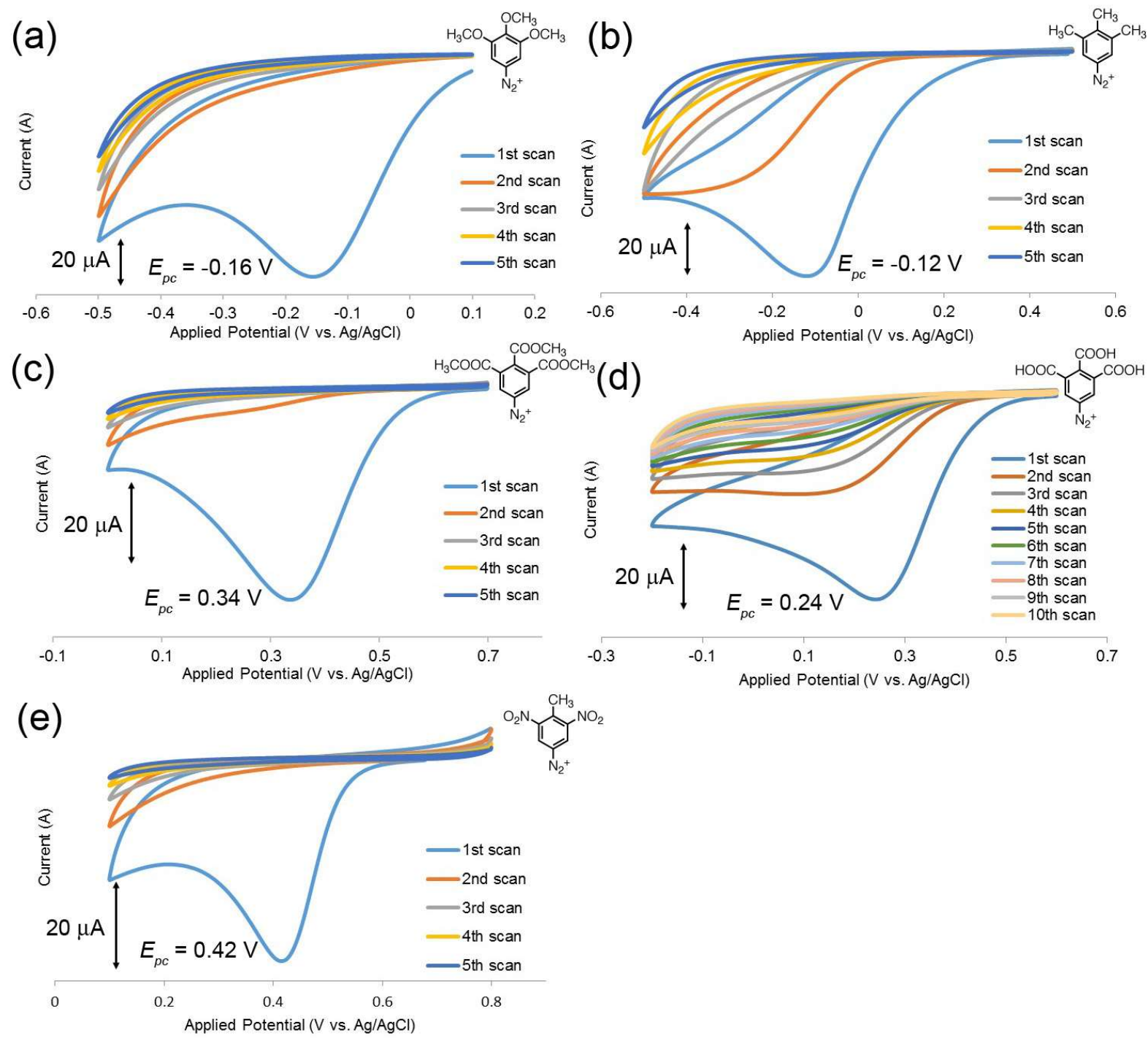

Figure 3. Cyclic voltammograms of aqueous solutions of aryldiazonium salts, $\mathbf{3 b} \cdot \mathbf{C l}(\mathrm{a}), \mathbf{4 b} \cdot \mathbf{C l}(\mathrm{b})$, $\mathbf{5 b} \cdot \mathbf{C l}$ (c), $\mathbf{6 b} \cdot \mathbf{C l}$ (d) and $\mathbf{7 b} \cdot \mathbf{C l}$ (e) using HOPG as a working electrode. Scan rate is $0.1 \mathrm{~V} / \mathrm{s}$. All potentials (V) are given against a $\mathrm{Ag} / \mathrm{AgCl}$ reference electrode. Expect for compound $\mathbf{6 b} \cdot \mathbf{C l}$, the number of the $\mathrm{CV}$ cycles are five. Ten $\mathrm{CV}$ cycles were performed for compound $\mathbf{6 b} \cdot \mathbf{C l}$ to complete the reduction. For all measurements, the concentration of the anilines is $1.0 \mathrm{mM}$. 
Table 3. Reduction Potentials of Aryldiazonium Salts $\mathbf{2 b} \cdot \mathbf{C l}-\mathbf{7} \mathbf{b} \cdot \mathbf{C l}$ in Cyclic Voltammetry.

\begin{tabular}{|c|c|c|}
\hline diazonium salt & substituents & $\begin{array}{c}\text { reduction } \\
\text { potential, } E_{\mathrm{pc}}(\mathrm{V})^{a}\end{array}$ \\
\hline $\mathbf{2 b} \cdot \mathbf{C l}$ & $\mathrm{C}\left(\mathrm{CH}_{3}\right)_{3}$ & -0.17 \\
\hline $\mathbf{3 b} \cdot \mathbf{C l}$ & $\mathrm{OCH}_{3}$ & -0.16 \\
\hline $\mathbf{4 b} \cdot \mathbf{C l}$ & $\mathrm{CH}_{3}$ & -0.12 \\
\hline $\mathbf{5 b} \cdot \mathbf{C l}$ & $\mathrm{COOCH}_{3}$ & 0.34 \\
\hline $\mathbf{6 b} \cdot \mathbf{C l}$ & $\mathrm{COOH}_{3}$ & 0.24 \\
\hline $\mathbf{7 b} \cdot \mathbf{C l}$ & $\mathrm{NO}_{2}, \mathrm{CH}_{3}$ & 0.42 \\
\hline
\end{tabular}

${ }^{a}$ Peak potentials $\left(E_{\mathrm{pc}}\right)$ against a $\mathrm{Ag} / \mathrm{AgCl}$ reference electrode.

\section{Raman Spectra of Functionalized Graphite}

After EC treatment, the graphite surface was removed from the EC cell, washed with ultrapure water $(18.2 \mathrm{M} \Omega \cdot \mathrm{cm})$ and distilled acetone, and dried with a nitrogen flow. These dried samples were used for Raman analyses and STM and AFM characterizations.

First, the surfaces were analyzed by Raman microscopy. Raman spectra of pristine graphite or graphene exhibit intense G- and 2D-peaks around $1580 \mathrm{~cm}^{-1}$ and $2700 \mathrm{~cm}^{-1}$, respectively. In addition, the D-peak is activated by lattice defects including those due to $\mathrm{sp}^{3}$-hybridization (Figure 4a). ${ }^{50}$ Thus, Raman spectroscopy directly gives information on the formation of $\mathrm{sp}^{3}$-hybridized carbon atoms resulting from the formation of covalent bonds. The intensity ratio of the D- and G-peaks $\left(I_{\mathrm{D}} / I_{\mathrm{G}}\right)$ is often used as a measure of the degree of covalent functionalization. ${ }^{50}$ For each sample, Raman spectra at 9 or 16 different positions with 20.0 or $13.3 \mu \mathrm{m}$ spacing in $\mathrm{x}$ - and y-directions $(3 \times 3$ or $4 \times 4$ matrix) were acquired for an excitation laser wavelength of $532 \mathrm{~nm}$. Figure 4 displays typical Raman spectra of functionalized graphite surfaces using $\mathbf{3 b} \cdot \mathbf{C l}-\mathbf{7 b} \cdot \mathbf{C l}$. In all cases, in addition to the intense G- and 2D-peaks at $1581 \mathrm{~cm}^{-1}$ and $2700 \mathrm{~cm}^{-1}$, respectively, a D-peak appears at $1349 \mathrm{~cm}^{-1}$, proving the formation of $\mathrm{sp}^{3}$-hybridized carbons by grafting. Averaged $I_{\mathrm{D}} / I_{\mathrm{G}}$ values over 9 or 16 spectra are summarized in Table 4 . The average $I_{\mathrm{D}} / I_{\mathrm{G}}$ of the functionalized graphite surfaces by $\mathbf{3 b} \cdot \mathbf{C l}$ and $\mathbf{6 b} \cdot \mathbf{C l}$ are $0.068 \pm 0.002$ and $0.056 \pm 0.003$, respectively (Figures $4 \mathrm{a}, \mathrm{d})$. For comparison, $I_{\mathrm{D}} / I_{\mathrm{G}}$ of $\mathbf{2 b} \cdot \mathbf{C l}$ is $0.064 \pm 0.002 .{ }^{23}$ These relatively large $I_{\mathrm{D}} / I_{\mathrm{G}}$ indicate a high density of $\mathrm{sp}^{3}$ carbon atoms. On the other hand, smaller $I_{\mathrm{D}} / I_{\mathrm{G}}$ of $0.030 \pm 0.001,0.024 \pm 0.001$ and $0.017 \pm 0.001$ are recorded for those functionalized by $\mathbf{4 b} \cdot \mathbf{C l}, \mathbf{5} \mathbf{b} \cdot \mathbf{C l}$ and $\mathbf{7 b} \cdot \mathbf{C l}$, respectively (Figures $4 \mathrm{~b}, \mathrm{c}, \mathrm{e})$, indicating less efficient grafting on these surfaces. The different grafting densities suggest that the electronic properties of the substituent groups affect the efficiency of functionalization. 

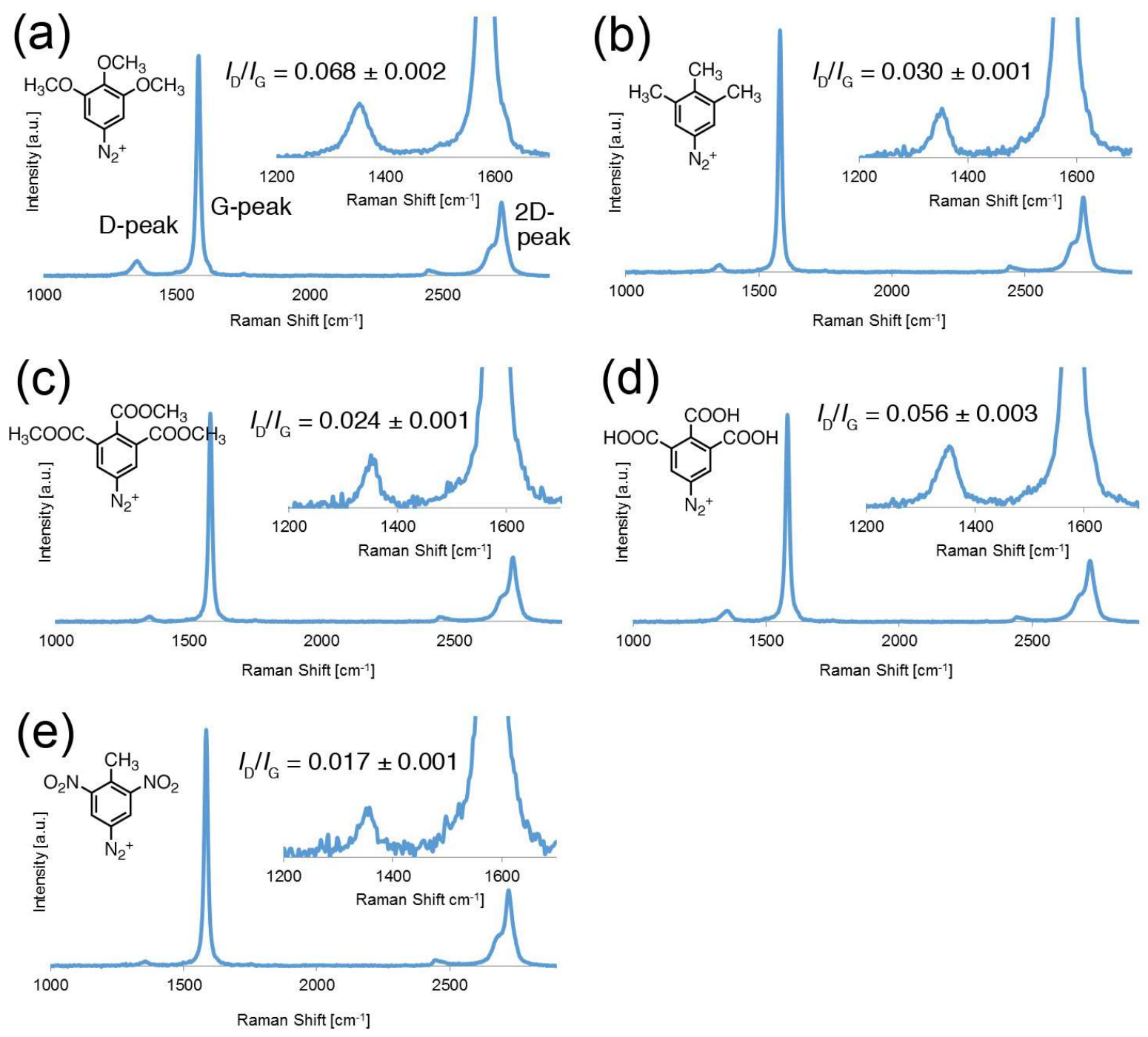

Figure 4. Typical Raman spectra of graphite functionalized using aryldiazonium salts, $\mathbf{3 b} \cdot \mathbf{C l}(\mathrm{a})$, $\mathbf{4 b} \cdot \mathbf{C l}(\mathrm{b}), \mathbf{5 b} \cdot \mathbf{C l}(\mathrm{c}), \mathbf{6 b} \cdot \mathbf{C l}(\mathrm{d})$ and $\mathbf{7 b} \cdot \mathbf{C l}(\mathrm{e}) . I_{\mathrm{D}} / I_{\mathrm{G}}$ ratios are $0.068 \pm 0.002(\mathrm{a}), 0.030 \pm 0.001(\mathrm{~b})$, $0.024 \pm 0.001(\mathrm{c}), 0.056 \pm 0.003(\mathrm{~d})$ and $0.017 \pm 0.001(\mathrm{e})$, respectively. 
Table 4. Ratios of Intensities of $\mathrm{D}$ and G Peaks $\left(I_{\mathrm{D}} / I_{\mathrm{G}}\right)$ of Raman Spectra, Number of Bright Dots in STM Images and AFM Estimated Thickness of Deposited Layers of Functionalized Graphite Surfaces Using Aryldiazonium Salts $\mathbf{2 b} \cdot \mathbf{C l}-\mathbf{7 b} \cdot \mathbf{C l}$.

\begin{tabular}{|c|c|c|c|c|c|c|}
\hline \multirow[b]{2}{*}{$\begin{array}{c}\text { diazonium } \\
\text { salt }\end{array}$} & \multirow[b]{2}{*}{ substituents } & \multicolumn{4}{|c|}{ high concentration $[1 \mathrm{mM}]$} & \multirow{2}{*}{$\begin{array}{c}\text { low concentration } \\
{[0.3 \mathrm{mM}]} \\
I_{\mathrm{D}} / I_{\mathrm{G}}{ }^{a}\end{array}$} \\
\hline & & $I_{\mathrm{D}} / I_{\mathrm{G}}{ }^{a}$ & $\begin{array}{c}\text { FWHM (G) } \\
\left(\mathrm{cm}^{-1}\right)^{a, b}\end{array}$ & $\begin{array}{c}\text { number of } \\
\text { bright dots } \\
\left(\mu \mathrm{m}^{-2}\right)^{c}\end{array}$ & $\begin{array}{c}\text { film } \\
\text { thickness } \\
(\mathrm{nm})^{e}\end{array}$ & \\
\hline $2 \mathrm{~b} \cdot \mathrm{Cl}$ & $\mathrm{C}\left(\mathrm{CH}_{3}\right)_{3}$ & $\begin{array}{c}0.064 \\
\pm 0.002\end{array}$ & $14.7 \pm 0.5$ & N.D. ${ }^{d}$ & 0.7 & $\begin{array}{c}0.013 \\
\pm 0.001\end{array}$ \\
\hline $3 b \cdot C l$ & $\mathrm{OCH}_{3}$ & $\begin{array}{c}0.068 \\
\pm 0.002\end{array}$ & $17.2 \pm 0.1$ & N.D. ${ }^{d}$ & 1.0 & $\begin{array}{c}0.027 \\
\pm 0.002\end{array}$ \\
\hline $4 b \cdot C l$ & $\mathrm{CH}_{3}$ & $\begin{array}{c}0.030 \\
\pm 0.001\end{array}$ & $14.6 \pm 0.1$ & $\begin{array}{l}38000 \\
\pm 6000\end{array}$ & 0.6 & $\begin{array}{c}0.010 \\
\pm 0.002\end{array}$ \\
\hline $5 \mathbf{b} \cdot \mathbf{C l}$ & $\mathrm{COOCH}_{3}$ & $\begin{array}{c}0.024 \\
\pm 0.001\end{array}$ & $15.2 \pm 0.3$ & $\begin{array}{r}43000 \\
\pm 9000\end{array}$ & 0.6 & $\begin{array}{c}0.008 \\
\pm 0.002\end{array}$ \\
\hline $6 b \cdot C l$ & $\mathrm{COOH}$ & $\begin{array}{c}0.056 \\
\pm 0.003\end{array}$ & $16.3 \pm 0.7$ & N.D. ${ }^{d}$ & $1.6^{f}$ & $\begin{array}{c}0.005 \\
\pm 0.002\end{array}$ \\
\hline $7 \mathrm{~b} \cdot \mathrm{Cl}$ & $\mathrm{NO}_{2}, \mathrm{CH}_{3}$ & $\begin{array}{c}0.017 \\
\pm 0.002\end{array}$ & $16.0 \pm 0.2$ & $\begin{array}{l}29000 \\
\pm 3000\end{array}$ & 0.6 & $\begin{array}{c}0.016 \\
\pm 0.001\end{array}$ \\
\hline
\end{tabular}

${ }^{a}$ Average values of 9 or 16 different positions. Average $I_{\mathrm{D}} / I_{\mathrm{G}}$ of pristine graphite is $0.002 .{ }^{b}$ Full width at half maximums (FWHM) of the G peaks. Average FWHM(G) of pristine graphite is $15.0 \pm 0.1 \mathrm{~cm}^{-}$ 1. While $\operatorname{FWHM}(\mathrm{G})$ is used as a parameter of graphitization, a correlation between $I_{\mathrm{D}} / I_{\mathrm{G}}$ and $\mathrm{FWHM}(\mathrm{G}) \mathrm{s}$ is not found maybe because of effect of grafted molecular species, but more likely because of the contribution of the underlying graphene layers which remain unaffected by grafting. ${ }^{c}$ Average numbers of bright dots per $\mu \mathrm{m}^{2}$. More than 9 large area STM images $(200 \mathrm{~nm} \times 200 \mathrm{~nm}, 100$ $\mathrm{nm} \times 100 \mathrm{~nm}$ or $50 \mathrm{~nm} \times 50 \mathrm{~nm}$ ) were used for the analysis. Number of the bright dots as counted by eye. ${ }^{d}$ The number of bright dots could not be determined because of too dense coverage of the surfaces functionalized by $\mathbf{2 b} \cdot \mathbf{C l}$ and $\mathbf{3 b} \cdot \mathbf{C l}$ and because of the streaky images in the case of $\mathbf{6 b} \cdot \mathbf{C l} .^{e}$ For determination of the film thickness, we need to define apparent heights of the films and bare graphite surfaces. To define the film height, we selected maximum height values at each peak from the line profile. Then, the maximum height values at each peak are averaged. For the height of bare graphite plane, the apparent height of all pixels in flat bare graphite area are averaged. Height difference between the film and the bare graphite corresponds to the film thickness. ${ }^{f}$ The thickness of 
the layer was reduced to $0.5-0.7 \mathrm{~nm}$ after washing with an aqueous solution of $\mathrm{NaOH}(1 \mathrm{M}$, see Figure S11 in Supporting Information).

\section{STM Characterization of Functionalized Graphite Surfaces}

Functionalized graphite surfaces were characterized by means of STM under ambient conditions to visualize individual sites of covalent grafting (Figure 5). There are randomly distributed bright dots with diameters of $1-3 \mathrm{~nm}$ on the grafted surfaces using $\mathbf{4 b} \cdot \mathbf{C l}, \mathbf{5 b} \cdot \mathbf{C l}$ and $\mathbf{7 b} \cdot \mathbf{C l}(1 \mathrm{mM})$. We assign these bright dots to covalently bound aryl groups because similar grain-like features were previously observed for the functionalized graphite surface using $\mathbf{2 b} \cdot \mathbf{C l}$ under similar conditions. ${ }^{23}$ Table 4 summarizes average numbers of such bright dots per $\mu^{2}$, which are ca. $38000 \pm 6000,43000$ \pm 9000 , and $29000 \pm 3000$ for $\mathbf{4 b} \cdot \mathbf{C l}, \mathbf{5} \mathbf{b} \cdot \mathbf{C l}$ and $\mathbf{7 b} \cdot \mathbf{C l}$, respectively. However, in the case of functionalized surfaces by $\mathbf{3 b} \cdot \mathbf{C l}$ and $\mathbf{6 b} \cdot \mathbf{C l}$, individual dots are not distinguished in the STM images because of too high grafting density similar to the case of $\mathbf{2 b} \cdot \mathbf{C l}$. Moreover, there are some brighter dots in Figure 5a and grains in Figure 5d, which is possibly attributed to deposited molecular impurity(ies) on the top of the monolayers. However, these results indicate that the grafting density estimated by $I_{\mathrm{D}} / I_{\mathrm{G}}$ is positively correlated with the number of the bright dots in the STM images. In addition, it should be noted that the observed number of the dots may involve deviations due to detachment of the aryl groups by STM tip scanning. ${ }^{23,51}$ In fact, the number of the bright dots gradually decreased after STM tip scans at certain tunneling conditions (high tunneling current: larger than 200 pA, low bias voltages: from $-10 \mathrm{mV}$ to $-20 \mathrm{mV}) .{ }^{23}$ We noticed that the persistency of the grafted aryl units toward tip scans differs depending on the grafted aryl groups. In particular, grafted species formed by $\mathbf{6 b} \cdot \mathbf{C l}$ were removed even at very low tunneling current of $2 \mathrm{pA}$, as indicated by the many streaky lines in the images at that tunneling current (Figure 5d). Similarly, the number of the bright dots formed by $\mathbf{7 b} \cdot \mathbf{C l}$ was gradually decreased by scanning even at a low tunneling current (60 pA) as indicated by a few streak images in Figure 5e. It seems that the grafted aryl units with the electron-withdrawing groups are relatively easily removed by tip scanning. We do not understand the reason for the substituent effect on degrafting. However, to gain insight into the relative ease of heterolytic cleavage of the $\mathrm{C}-\mathrm{C}$ bonds connected to aryl groups of different electronic properties, heterolytic cleavage energies were estimated theoretically using simple model systems by DFT calculations. For this purpose, heterolysis of 1-tert-butyl-3,4,5-trimethoxybenzene and 1-tert-butyl-4-methyl-3,5-dinitrobenzene, which are the models of functionalized surface with $\mathbf{7 b} \cdot \mathbf{C l}$ and $\mathbf{3 b} \cdot \mathbf{C l}$, respectively, producing the corresponding aryl anions and a tert-butyl cation was used (Scheme S1). As a result, C-C bond strength for the former turned out to be relatively weak compared to the latter (Table S3). This correlates to the sensitivity toward tip scanning under the negative 
sample bias voltage.
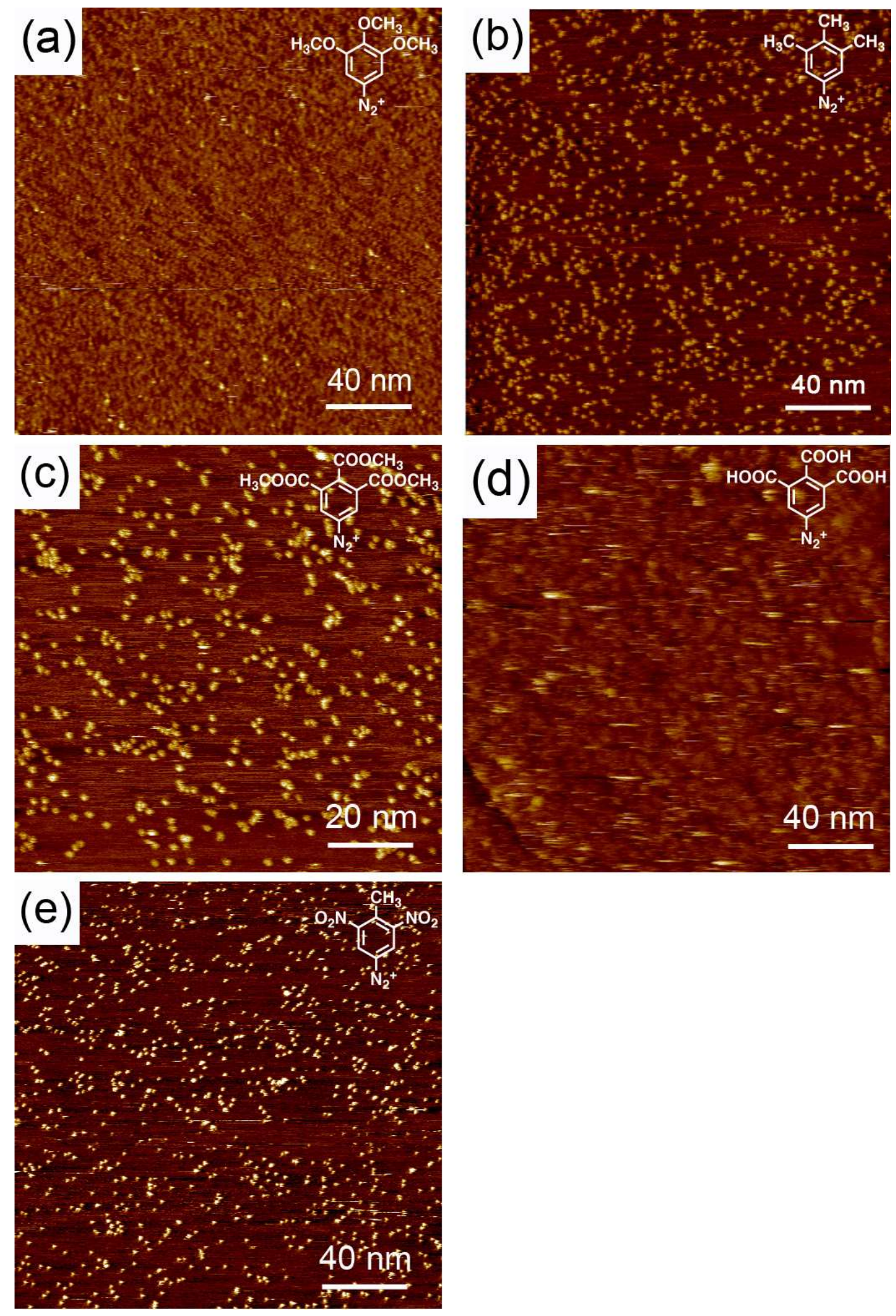

Figure 5. Typical STM images of functionalized graphite surfaces using diazonium salts, $\mathbf{3 b} \cdot \mathbf{C l}(\mathrm{a})$, $\mathbf{4 b} \cdot \mathbf{C l}(\mathrm{b}), \mathbf{5 b} \cdot \mathbf{C l}(\mathrm{c}), \mathbf{6 b} \cdot \mathbf{C l}(\mathrm{d})$ and $\mathbf{7 b} \cdot \mathbf{C l}(\mathrm{e})$. Tunneling conditions are (a) $I_{\text {set }}=15 \mathrm{pA}, V_{\text {bias }}=-600$ $\mathrm{mV}$, (b) $I_{\text {set }}=60 \mathrm{pA}, V_{\text {bias }}=-800 \mathrm{mV}$, (c) $I_{\text {set }}=60 \mathrm{pA}, V_{\text {bias }}=-800 \mathrm{mV}$, (d) $I_{\text {set }}=2 \mathrm{pA}, V_{\text {bias }}=-500 \mathrm{mV}$, 
and (e) $I_{\text {set }}=60 \mathrm{pA}, V_{\text {bias }}=-800 \mathrm{mV}$, respectively.

\section{AFM Characterization of Functionalized Graphite Surfaces.}

Next, we utilized AFM to gain topographical information of the functionalized graphite surfaces under ambient conditions. Additionally, grafted layers were removed by scratching with an AFM tip, by which the bare graphite surface is exposed, to determine the thickness of the grafted layer. Figure 6 shows AFM images of functionalized graphite surfaces acquired in an acoustic AC mode. Dark areas in the image centers correspond to the exposed bare graphite surfaces. Height profiles along white lines in each image are also displayed in Figure 6. The height profiles show surface height variation of ca. $0.5-0.7 \mathrm{~nm}$ for all samples, indicating a high degree of height uniformity. Moreover, the height differences between the grafted layers formed by $\mathbf{3 b} \cdot \mathbf{C l}-\mathbf{5 b} \cdot \mathbf{C l}$ and $7 \mathbf{b} \cdot \mathbf{C l}$ and the bare graphite surface are ca. $0.6-1.0 \mathrm{~nm}$ in accord with monolayer thickness. On the other hand, the height difference is ca. $1.6 \mathrm{~nm}$ for the grafted layer of $\mathbf{6 b} \cdot \mathbf{C l}$. This corresponds to the height of two or three molecular units deposited on surfaces (Figure S10). We hypothesize that the thick layer is due to the deposition of byproducts, such as 1,2,3-benzenetricarboxylic acid, bound via hydrogen bonding between the carboxy groups of the covalently grafted aryl group. ${ }^{52}$ In fact, the film height was significantly reduced after washing with an aqueous solution of $\mathrm{NaOH}(1 \mathrm{M})$ to $0.5-0.7$ $\mathrm{nm}$ (Figures S11 and S12), thus supporting the above hypothesis. In contrast, such height reduction was not observed for the reference sample, functionalized surface with $\mathbf{2 b} \cdot \mathbf{C l}$ (Figure S13). These results indicate that substituents at the 3,4,5-positions of the benzene ring of aryldiazonium ions successfully block the multilayer growth. 

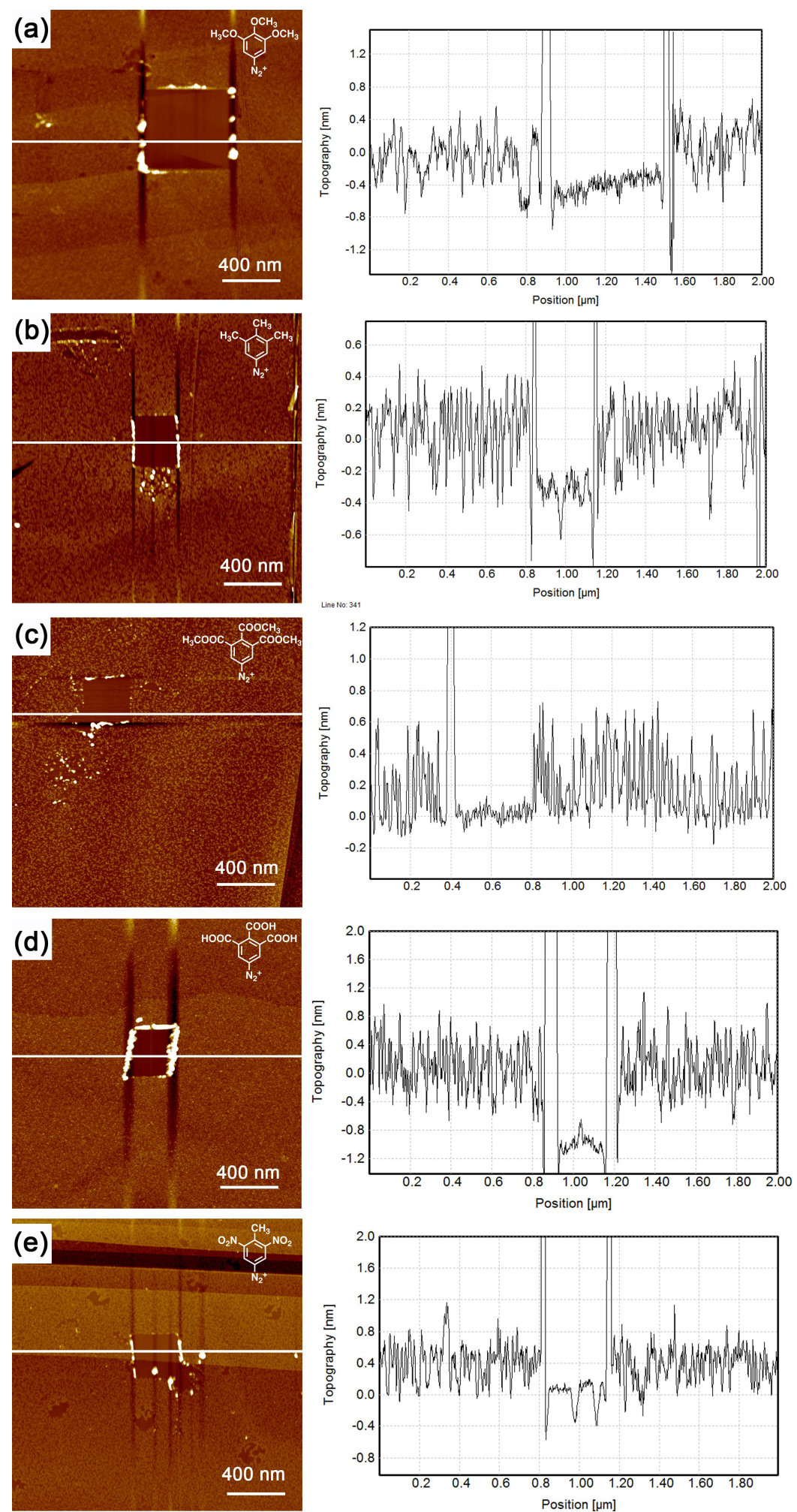

Figure 6. Typical AFM height images of functionalized graphite surfaces using diazonium salts, $\mathbf{3 b} \cdot \mathbf{C l}(\mathrm{a}), \mathbf{4 b} \cdot \mathbf{C l}(\mathrm{b}), \mathbf{5 b} \cdot \mathbf{C l}(\mathrm{c}), \mathbf{6 b} \cdot \mathbf{C l}$ (d) and $\mathbf{7 b} \cdot \mathbf{C l}(\mathrm{e})$. The grafted species at the darker area (500 $\mathrm{nm} \times 500 \mathrm{~nm}$ (a) and $300 \mathrm{~nm} \times 300 \mathrm{~nm}(\mathrm{~b}-\mathrm{e}))$ of the images were removed by AFM tip scratching. Thickness of the organic layers is determined by the height analysis along a white line in each image. 


\section{DISSCUSSION}

All aryl radicals have shown to graft graphite surfaces successfully producing functionalized surfaces. AFM investigations revealed that all grafted layers are monolayers indicating that introduction of substituents at the 3,4,5-positions of the benzene ring suppresses multilayer growth irrespective of their electronic nature. On the other hand, $I_{\mathrm{D}} / I_{\mathrm{G}}$ values determined from the Raman spectra and the apparent grafting densities estimated by STM observation showed that the grafting density varied depending on the electronic properties of the aryl substituents. Compounds $\mathbf{2} \mathbf{b} \cdot \mathbf{C l}$ and $\mathbf{3 b} \cdot \mathbf{C l}$ with electron donating groups show higher grafting densities, compound $\mathbf{4 b} \cdot \mathbf{C l}$ with the methyl groups exhibits a medium density, and the other compounds $\mathbf{5 b} \cdot \mathbf{C l}$ and $\mathbf{7 b} \cdot \mathbf{C l}$ with electron-withdrawing groups give lower grafting densities. Here, plausible factors that influence the grafting density are discussed.

As mentioned above, except for compound $\mathbf{7 b} \cdot \mathbf{C l}$, the half-life time of the aryldiazonium salts is longer than $100 \mathrm{~min}$ (Table 2). The half-life time of $\mathbf{7 b} \cdot \mathbf{C l}$ is very short (ca. $10 \mathrm{~min}$ ) which is one of the reasons for the lowest grafting density recorded for $\mathbf{7 b} \cdot \mathbf{C l}$.

Next, we analyzed the currents for the reduction of the aryldiazonium salts. Table S6 summarizes the calculated total charges. In general, the compounds having electron-donating groups show larger total charges compared to those of the aryldiazonium salts having electron-withdrawing groups. The total charge differences are related to diffusion and reaction rates of the aryldiazonium salts at the electrode. Since grafting of the compounds with electron-withdrawing groups is relatively slower, it is unlikely that the current is limited only by covalent coverage of the surface. Other factors should operate.

Previously, the effect of dipole moment of aryl radicals on the grafting rates to $\mathrm{Si}(111)$ surface was inferred. ${ }^{34}$ To examine if there is any correlation of the molecular dipole moment with the observed grafting density, we performed DFT simulations (see Tables S4 and S5). Though the molecular dipole moments in some of the conformers are not coplanar with respect to the plane of the aryl group due to steric congestion between the functional groups, at large they vary significantly in accordance with the electronic character of the substituents. It is possible therefore that aryl radicals with (an) electron-withdrawing group(s) may be adsorbed perpendicularly on the surface orienting the positive end (radical side) to the surface as previously suggested. ${ }^{34}$ Despite the favorable orientation for addition to the surface, the grafting efficiency of electron-deficient radicals are low. The transient pre-adsorption of aryl radicals and also aryldiazonium ions may also contribute to reducing the grafting efficiency, which is reflected in the smaller current flow as described above.

It was pointed out that substituent effect on reduction potentials of aryl radicals is modest, because a large variation in the electron affinity is counteracted by an opposing variation in the 
solvation energy. ${ }^{46}$ Nevertheless, we hypothesize that an additional factor to influence grafting efficiency is the intrinsic reactivity of the aryl radicals. In radical chemistry, a match in the energy levels of molecular orbitals between reactants is critical for reaction efficiency. ${ }^{53}$ SOMO energy levels of the electron rich radicals are relatively close to the Fermi level of graphite $(-4.7 \mathrm{eV}) .{ }^{54,55}$ Indeed, compounds $\mathbf{2} \mathbf{b} \cdot \mathbf{C l}$ and $\mathbf{3 b} \cdot \mathbf{C l}$ showed higher grafting density. However, there are two exceptions from this hypothesis. One is compound $\mathbf{6 b} \cdot \mathbf{C l}$. This compound shows high grafting density, while the SOMO energy level is not close to the Fermi level. Though the reason is not clear, we consider that this relates to the formation of hydrogen bonded dimers, trimers or higher aggregates in an aqueous solution phase. Intermolecular hydrogen bonding should be favored over intramolecular hydrogen bonding for the formation of such aggregates. DFT simulations confirm that conformers with two intramolecular hydrogen bonds among three carboxy groups show a higher total energy due to steric strain (see Table S1 in Supporting Information). Though acid dimer formation in water is unlikely for simple organic acids such as acetic acid, we suppose that an amphiphilic nature due to three carboxy acid groups and hydrophobic benzene ring of $\mathbf{6 b} \cdot \mathbf{C l}$ facilitate aggregation. This would influence a SOMO energy level. To support this hypothesis, we performed grafting experiments using solutions at lower concentrations of the aryl diazonium salts $(0.3 \mathrm{mM})$, where dimer or trimer formation is less favorable. In all compounds, $I_{\mathrm{D}} / I_{\mathrm{G}}$ of the Raman spectra of functionalized graphite surfaces decreased by three to ten times compared to the respective $I_{\mathrm{D}} / I_{\mathrm{G}}$ at 1 $\mathrm{mM}$ except for $\mathbf{7 b} \cdot \mathbf{C l}$ of which the concentration was not certain due to instability. Notably, the reduction of ten times in $I_{\mathrm{D}} / I_{\mathrm{G}}$ was recorded for $\mathbf{6 b} \cdot \mathbf{C l}$ (Table 4). The reduction magnitude was remarkably larger than those of other aryldiazoniums (3-5 times). This result supports the above hypothesis; in the case of $\mathbf{6 b} \cdot \mathbf{C l}$ the concentration of more reactive (aggregated) species must be reduced due to equilibrium shift in addition to the consequence of lowering concentration of all diazonium species. The second rare case is compound $\mathbf{4 b} \cdot \mathbf{C l}$. While the SOMO energy levels of compounds $\mathbf{4 b} \cdot \mathbf{C l}$ and $\mathbf{2 b} \cdot \mathbf{C l}$ are almost the same, the average $I_{\mathrm{D}} / I_{\mathrm{G}}$ of the functionalized graphite surfaces are different $(0.030$ for $\mathbf{4 b} \cdot \mathbf{C l}$ and 0.064 for $\mathbf{2 b} \cdot \mathbf{C l})$. We attribute this to aryl radical quenching by hydrogen abstraction from the methyl groups of the grafted aryl unit. ${ }^{56}$ Despite these exceptions, we suggest that energy level matching between SOMO levels of aryl radicals and Fermi level of surfaces affects grafting efficiency at least to some extent.

\section{SUMMARY}

In summary, we have studied the EC functionalization of graphite using aryldiazonium salts $\mathbf{2 b} \cdot \mathbf{C l}-\mathbf{7 b} \cdot \mathbf{C l}$ having electron-donating or -withdrawing groups at the 3,4,5-positions. Moreover, we performed nano- and micrometer scale characterization of the functionalized surfaces using AFM, 
STM, and Raman microscopy. AFM investigation of the modified surfaces revealed the exclusive formation of monolayers for all aryldiazonium salts. Therefore, all functional groups investigated, nitro, carboxy, ester, methyl and methoxy groups, at the 3,4,5-positions of the benzene ring suppress polyaryl growth. STM observation and Raman $I_{\mathrm{D}} / I_{\mathrm{G}}$ mapping of the modified surfaces indicate that the degree of grafting depends on the electronic state of the aryl radicals. The radicals with electron-donating groups show a high degree of functionalization, while those with electron-withdrawing groups exhibit a low degree of functionalization. We suggest that this relates to the electronic property of the aryl radicals. The understanding of the chemical functionalization of graphite or graphene and its impact on the electronic and surface properties, ${ }^{57}$ are important for the production of tailored carbon materials. 


\section{ASSOCIATED CONTENT}

\section{Supporting Information}

Experimental details, synthesis of $\mathbf{5 a}$, washing procedure of functionalized HOPG by $\mathbf{6 a}$, model of the bilayer formed by $\mathbf{6 a}$, details of formation and dediazoniation for aryldiazonium salts, and results of post functionalization. This material is available free of charge via the Internet at http://pubs.acs.org.

\section{AUTHOR INFORMATION}

\section{Corresponding Author}

*tahara@meiji.ac.jp

*steven.defeyter@kuleuven.be

*tobe@chem.es.osaka-u.ac.jp

\section{ORCID}

Kazukuni Tahara: 0000-0002-3634-541X

Brandon Hirsch: 0000-0002-3452-0990

Steven De Feyter: 0000-0002-0909-9292

Yoshito Tobe: 0000-0002-1795-5829

\section{Notes}

The authors declare no competing financial interest.

\section{Acknowledgement}

This work is supported by JST-PRESTO "Molecular technology and creation of new functions", and JSPS KAKENHI (15H02164, 17H04794), the Fund of Scientific Research Flanders (FWO), KU Leuven - Internal Funds, the European Research Council under the European Union's Seventh Framework Programme (FP7/2007-2013)/ERC Grant Agreement No. 340324 to S.D.F. B.E.H. thanks FWO for a postdoctoral fellowship and the Belgian-American Educational Foundation. A.B. thanks Fonds Wetenschappelijk Onderzoek (FWO) for personal fellowship. 


\section{REFERENCE}

1. McCreery, R.; Bergren, A. J. Diazonium Compounds in Molecular Electronics. In Aryl Diazonium Salts; Chehimi, M. M. Ed.; Wiley-VCH Verlag \& Co. KGaA: Weinheim, 2012; pp 219-239.

2. Assresahegn, B. D.; Brousse, T.; Belanger, D. Advances on the Use of Diazonium Chemistry for Functionalization of Materials Used in Energy Storage Systems. Carbon 2015, 92, 362 381.

3. Guo, L.; Zhang, Y.; Wang, J.; Ma, L.; Ma, S.; Zhang, Y.; Wang, E.; Bi, Y.; Wang, D.; McKee, W. C.; Xu, Y.; Chen, J.; Zhang, Q.; Nan, C.; Gu, L.; Bruce, P. G.; Peng, Z. Unlocking the Energy Capabilities of Micron-Sized $\mathrm{LiFePO}_{4}$. Nat. Commun. 2015, 6, 7898.

4. Cao, C.; Zhang, Y.; Jiang, C.; Qi, M.; Liu, G. Advances on Aryldiazonium Salt Chemistry Based Interfacial Fabrication for Sensing Applications. ACS Appl. Mater. Interfaces 2017, 9 , 5031-5049.

5. Downard, A. J.; Gross, A. J.; Simons, B. M. Patterned Molecular Layers on Surfaces. In Aryl Diazonium Salts; Chehimi, M. M. Ed.; Wiley-VCH Verlag \& Co. KGaA: Weinheim, 2012; pp $53-69$.

6. Belmont, J. A.; Bureau, C.; Chehimi, M. M.; Gam-Derouich, S.; Pinson, J. Patents and Industrial Applications of Aryl Diazonium Salts and Other Coupling Agents. In Aryl Diazonium Salts; Chehimi, M. M. Ed.; Wiley-VCH Verlag \& Co. KGaA: Weinheim, 2012; pp 309-321.

7. Pinson, J.; Podvorica, F. Attachment of Organic Layers to Conductive or Semiconductive Surfaces by Reduction of Diazonium Salts. Chem. Soc. Rev. 2005, 34, 429-439.

8. Berisha, A.; Chehimi, M. M.; Pinson, J.; Podvorica, F. I. Electrode Surface Modification using Diazonium Salts. In Electroanalytical Chemistry; Bard, A. J., Zoski, C. G., Eds.; CRC Press; Taylor \& Francis Group: New York, 2016; Vol. 26, pp 115-223.

9. Adenier, A.; Cabet-Deliry, E.; Chaussé, A.; Griveau, S.; Mercier, F.; Pinson, J.; Vautrin-U1, C. Grafting of Nitrophenyl Groups on Carbon and Metallic Surfaces without Electrochemical Induction. Chem. Mater. 2015, 17, 491-501.

10. Adenier, A.; Barré, N.; Cabet-Deliry, E.; Chaussé, A.; Griveau, S.; Mercier, F.; Pinson, J.; Vautrin-U1, C. Study of the Spontaneous Formation of Organic Layers on Carbon and Metal Surfaces form Diazonium Salts. Surf. Sci. 2006, 600, 4801-4812.

11. Hurley, B. L.; McCreery, R. L. Covalent Bonding of Organic Molecules to $\mathrm{Cu}$ and Al Alloy 2024 T3 Surfaces via Diazonium Ion Reduction. J. Electrochem. Soc. 2004, 151, B252-B259.

12. Delamar, M.; Hitmi, R.; Pinson, J.; Savéant, J. M. Covalent Modification of Carbon Surfaces by 
Grafting of Functionalized Aryl Radicals Produced from Electrochemical Reduction of Diazonium Salts. J. Am. Chem. Soc. 1992, 114, 5883-5884.

13. Allongue, P.; Delamar, M.; Desbat, B.; Fagebaume, O.; Hitmi, R.; Pinson, J.; Savéant, J.-M. Covalent Modification of Carbon Surfaces by Aryl Radicals Generated from the Electrochemical Reduction of Diazonium Salts. J. Am. Chem. Soc. 1997, 119, 201-207.

14. Hinrichs, K.; Roodenko, K.; Rappich, J.; Chehimi, M. M.; Pinson, J. Analytical Methods for the Characterization of Aryl Layers. In Aryl Diazonium Salts; Chehimi, M. M. Ed.; Wiley-VCH Verlag \& Co. KGaA: Weinheim, 2012; pp 71-101.

15. Adenier, A.; Combellas, C.; Kanoufi, F.; Pinson, J.; Podvorica, F. I. Formation of Polyphenylene Films on Metal Electrodes by Electrochemical Reduction of Benzenediazonium Salts. Chem. Mater. 2006, 18, 2021-2029.

16. Doppelt, P.; Hallais, G.; Pinson, J.; Podvorica, F.; Verneyre, S. Surface Modification of Conducting Substrates. Existing of Azo Bonds in the Structure of Organic Layers Obtained from Diazonium Salts. Chem. Mater. 2007, 19, 4570-4575.

17. Zhang, X.; Rösicke, F.; Syritski, V.; Sun, G.; Reut, J.; Hinrichs, K.; Janietz, S.; Rappich, J. Influence of the Para-Substituent of Benzene Diazonium Salts and the Solvent on the Film Growth During Electrochemical Reduction. Z. Phys. Chem. 2014, 228, 557-573.

18. Combellas, C.; Kanoufi, F.; Pinson, J.; Podvorica, F. I. Sterically Hindered Diazonium Salts for the Grafting of a Monolayer on Metals. J. Am. Chem. Soc. 2008, 130, 8576-8577.

19. Combellas, C.; Jiang, D.; Kanoufi, F.; Pinson, J.; Podvorica, F. I. Steric Effects in the Reaction of Aryl Radicals on Surfaces. Langmuir 2009, 25, 286-293.

20. Anariba, F.; DuVall, S. H.; McCreery, R. L. Mono- and Multilayer Formation by Diazonium Reduction on Carbon Surfaces Monitored with Atomic Force Microscopy "Scratching". Anal. Chem. 2003, 75, 3837-3844.

21. Kariuki, J. K.; McDermott, M. T. Nucleation and Growth of Functionalized Aryl Films on Graphite Electrodes. Langmuir 1999, 15, 6534-6540.

22. Kariuki, J. K.; MacDermott, M. T. Formation of Multilayers on Glassy Carbon Electrodes via the Reduction of Diazonium Salts. Langmuir 2001, 17, 5947-5951.

23. Greenwood, J.; Phan, T. H.; Fujita, Y.; Li, Z.; Ivasenko, O.; Vanderlinden, W.; Van Gorp, H.; Frederickx, W.; Lu, G.; Tahara, K.; Tobe, Y.; Uji-i, H.; Mertens, S. F. L.; De Feyter, S. Covalent Modification of Graphene and Graphite Using Diazonium Chemistry: Tunable Grafting and Nanomanipulation. ACS Nano 2015, 9, 5520-5535.

24. Malmons, K.; Dong, M.; Pillai, S.; Kingshott, P.; Besenbacher, F.; Pedersen, S. U.; Daasbjerg, K. Using a Hydrazone-Protected Benzenediazonium Salt to Introduce a Near-Monolayer of 
Benzaldehyde on Glassy Carbon Surfaces. J. Am. Chem. Soc. 2009, 131, 4928-4936.

25. Leroux, Y. R.; Fei, H.; Noël, J.-M.; Roux, C.; Hapiot, P. Efficient Covalent Modification of a Carbon Surface: Use of a Silyl Protecting Group to Form an Active Monolayer. J. Am. Chem. Soc. 2010, 132, 14039-14041.

26. Leroux, Y. R.; Hapiot, P. Nanostructured Monolayers on Carbon Substrates Prepared by Electrografting of Protected Aryldiazonium Salts. Chem. Mater. 2013, 25, 489-495.

27. Mattiuzzi, A.; Jabin, I.; Mangeney, C.; Roux, C.; Reinaud, O.; Santos, L.; Bergamini, J.-F.; Hapiot, P.; Lagrost, C. Electrografting of Calix[4]arenediazonium Salts to Form Versatile Robust Platforms for Spatially Controlled Surface Functionalization. Nat. Commun. 2012, 3, 1130 .

28. Lee, L.; Gunby, N. R.; Crittenden, D. L.; Downard, A. J. Multifunctional and Stable Monolayers on Carbons: A Simple and Reliable Method for Backfilling Sparse Layers Grafted from Protected Aryldiazonium Ions. Langmuir 2016, 32, 2626-2637.

29. Menateau, T.; Levillain, E.; Breton, T. Electrografting via Diazonium Chemistry: From Multilayer to Monolayer Using Radical Scavenger. Chem. Mater. 2013, 25, 2905-2909.

30. Menateau, T.; Levillain, E.; Downard, A. J.; Breton, T. Evidence of Monolayer Formation via Diazonium Grafting with a Radical Scavenger: Electrochemical, AFM and XPS Monitoring. Phys. Chem. Phys. Chem. 2015, 17, 13137-13142.

31. Menanteau, T.; Dabos-Seignon, S.; Levillain, E.; Breton, T. Impact of the Diazonium Grafting Control on the Interfacial Reactivity: Monolayer versus Multilayer. ChemElectroChem 2017, 4, $278-282$.

32. Le Floch, F.; Simonato, J.-P.; Bidan, G. Electrochemical Signature of the Grafting of Diazonium Salts: a Probing Parameter for Monitoring the Electro-Addressed Functionalization of Device. Electrochimica Acta 2009, 54, 3078-3085.

33. Laforgue, A.; Addou, T.; Bélanger, D. Characterization of the Deposition of Organic Molecules at the Surface of Gold by the Electrochemical Reduction of Aryldiazonium Cations. Langmuir 2005, 21, 6855-6865.

34. Hartig, P.; Dittrich, Th.; Rappich, J. Surface Dipole Formation and Non-Radiative Recombination at p-Si(111) Surfaces during Electrochemical Deposition of Organic Layers. $J$. Electroanal. Chem. 2002, 524-525, 120-126.

35. Bouden, S.; Pinson, J.; Vautrin-U1, C. Electrografting of Diazonium Salts: A Kinetics Study. Electrochem. Commun. 2017, 81, 120-123.

36. Menanteau, T.; Dias M.; Levillain E.; Downard, A. J.; Breton, T. Electrografting via Diazonium Chemistry: The Key Role of the Aryl Substituent in the Layer Growth Mechanism. J. Phys. 
Chem. C 2016, 120, 4423-4429.

37. Chemical Functionalization of Carbon Nanomaterials: Chemistry and Applications. Thakur, V. K., Thakur, M. K. Eds.; CRC Press, Taylor \& Francis Group (2017).

38. De Volder, M. F. L.; Tawfick, S. H.; Baughman, R. H.; Hart, A. J. Carbon Nanotubes: Present and Future Commercial Applications. Science 2013, 339, 535-539.

39. Georgakilas, V.; Otyepka, M.; Bourlinos, A. B.; Chandra, V.; Kim, N.; Kemp, K. C.; Hobza, P.; Zboril, R.; Kim, K. S. Functionalization of Graphene: Covalent and Non-Covalent Approaches, Derivatives and Applications. Chem. Rev. 2012, 112, 6156-6214.

40. Hansch, C.; Leo, A.; Taft, R. W. A Survey of Hammett Substituent Constants and Resonance and Field Parameters. Chem. Rev. 1991, 91, 165-195.

41. Bragança, A. M.; Hirsch, B.; Sanz-Matias, A.; Hu, Y.; Walke, P.; Tahara, K.; Harvey, J. N.; Tobe, Y.; De Feyter, S. How Does Chemisorption Impacts Physisorption? A Molecular View of Defect Incorporation and Perturbation of 2D Self-Assembly. J. Phys. Chem. C. 2018, 122, 24046-24054.

42. Chira, A.; Bucur, B.; Radu, G.-L. Electrodeposited Organic Layers Formed from Aryl Diazonium Salts for Inhibition of Copper Corrosion. Materials 2017, 10, 235.

43. Martinez, Jr. O.; Crabtree, K. N.; Gottlieb, C. A.; Stanton, J. F.; McCarthy, M. C. An Accurate Molecular Structure of Phenyl, the Simplest Aryl Radical. Angew. Chem. Int. Ed. 2015, 54, $1808-1811$.

44. Bockman, T. M.; Kosynkin, D.; Kochi, J. K. Isolation and Structure Elucidation of Transient (Colored) Complexes of Arenediazonium with Aromatic Hydrocarbons as Intermediates in Arylations and Azo Couplings. J. Org. Chem. 1997, 62, 5811-5820.

45. Mayr, H.; Hartnagel, M.; Grimm, K. Quantification of the Electrophilicities of Diazonium Ions. Liebigs Ann. Recueil 1997, 55-69.

46. Koefoed, L.; Vase, K. H.; Stenlid, J. H.; Brinck, T.; Yoshimura, Y.; Lund, H.; Pedersen, S. U.; Daasbjerg, K. On the Kinetic and Thermodynamic Properties of Aryl Radicals Using Electrochemical and Theoretical Approaches. ChemElectroChem 2017, 4, 3212-3221.

47. Elofson, R. M.; Gadallah, F. F. Substituent Effects in the Polarography of Aromatic Diazonium Salts. J. Org. Chem. 1969, 34, 854-857.

48. Andrieux, C. P.; Pinson, J. The Standard Redox Potential of the Phenyl Radical/Anion Couple. J. Am. Chem. Soc. 2003, 125, 14801-14806.

49. Daasbjerg, K.; Sehested, K. Reduction of Substituted Benzenediazonium Salts by Solvated Electrons in Aqueous Neutral Solution Studied by Pulse Radiolysis. J. Phys. Chem. A 2002, 106, 11098-11106. 
50. Tuinstra, F.; Koenig, J. L. Raman Spectrum of Graphite. J. Chem. Phys. 1970, 83, 1126-1130.

51. Verstraete, L.; Greenwood, J.; Hirsch, B. E.; De Feyter, S. Self-Assembly under Confinement: Nanocorrals for Understanding Fundamentals of 2D Crystallization. ACS Nano 2016, 10, $10706-10725$.

52. Faucheux, A.; Gouget-Laemmel, A. C.; de Villeneuve, C. H.; Boukherroub, R.; Ozanam, F.; Allongue, P.; Chazalviel, J.-N. Well-Defined Carboxyl-Terminated Alkyl Monolayer Grafted onto G-Si(111): Packing Density from a Combined AFM and Quantitative IR Study. Langmuir 2006, 22, 153-162.

53. Fleming, I. Radical Reactions. In Frontier Orbitals and Organic Chemical Reactions; John Wiley \& Sons: United Kingdom, 2009; pp 275-298.

54. Feuerbacher, B.; Fitton, B. Experimental Investigation of Photoemission from Satellite Surface Materials. J. Appl. Phys. 1972, 43, 1563-1572.

55. Liu, D.; He, M.; Huang, C.; Sun, X.; Gao, B. Fermi Level Dependence of Chemical Functionalization of Graphene with Benzoyl Peroxide. J. Phys. Chem. C 2017, 121, 1054610551.

56. Kochi, J. K. Reactivity, Selectivity, and Polar Effects in Hydrogen Atom Transfer Reactions. In Free Radicals; Kochi, J. K. Ed.; John Wiley \& Sons: New York, 1973; pp 275-331.

57. Ferrari, A. C.; Bonaccorso, F.; Fal'ko, V.; Novoselov, K. S.; Roche, S.; Bøggild, P.; Borini, S.; Koppens, F. H. L.; Palermo, V.; Pungo, N.; Garrido, J. A.; Sordan, R.; Bianco, A.; Ballerini, L.; Prato, M.; Lidorikis, E.; Kivioja, J.; Marinelli, C.; Ryhänen, T.; Morpurgo, A.; Coleman, J. N.; Nicolosi, V.; Colombo, L.; Fert, A.; Garcia-Hernandez, M.; Bachtold, A.; Schneider, G. F.; Guinea, F.; Dekker, C.; Barbone, M.; Sun, Z.; Galiotis, C.; Grigorenko, A. N.; Konstantatos, G.; Kis, A.; Katsnelson, M.; Vandersypen, L.; Loiseau, A.; Morandi, V.; Neumaier, D.; Treossi, E.; Pellegrini, V.; Poloni, M.; Tredicucci, A.; Williams, G. M.; Hongm B. H.; Ahn, J.-H.; Kim, J. M.; Zirath, H.; van Wees, B. J.; van der Zant, H.; Occhipiniti, L.; Di Matteo, A.; Kinloch, I. A.; Seyller, T.; Quesnel, E.; Feng, X.; Teo, K.; Rupesinghe, N.; Hakonen, P.; Nei, S. R. T.; Tannock, Q.; Löfwander, T.; Kinaret, J. Science and Technology Roadmap for Graphene, Related Two-Dimensional Crystals, and Hybrid Systems. Nanoscale 2015, 7, 4587-5062. 
TOC graphics

Steric and Electronic Effects of Aryl Radicals on Grafitng

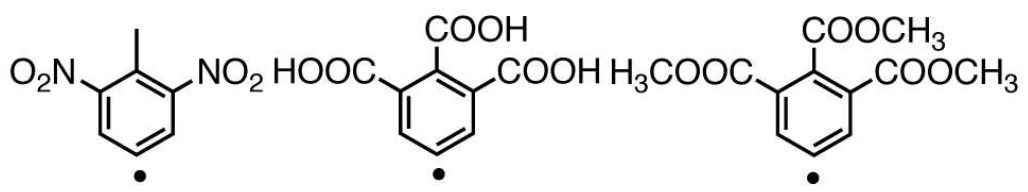

Electron-withdrawing
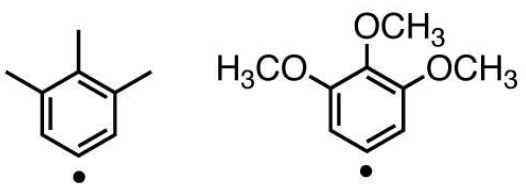

Electron-donating

All Molecules Form Monolayers on Graphite Surface Electronic Effect of Radicals Influences Grafting Density 